\title{
Un motor dins d'una ampolla de refresc
}

\author{
Josep Ametlla \\ IES Manolo Hugué, Caldes de Montbui
}

Amb materials senzills es tracta de construir un motor de corrent continu dins d'una ampoIla transparent que servirà de carcassa. Això permet visualitzar el funcionament de l'aparell $i$ comprendre el funcionament de les seves parts principals (rotor, col-lector, etc.).

Aquesta activitat pot ser interessant tant per a l'assignatura de Física i Química (crèdits variables a l'ESO) com per a la de Tecnologia. Abans de ferla caldrà haver parlat d'imants, pols, camp magnètic, electroimant... Jo l'he utilitzat també per a alumnes de currículum adaptat, des d'un punt de vista únicament manipulatiu.

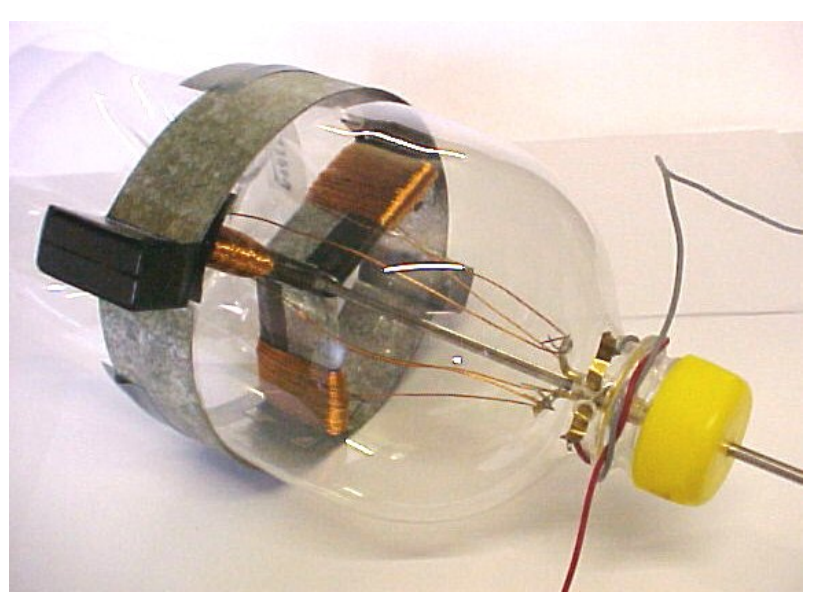

\section{MATERIAL}

- Ampolla de refresc, de plàstic transparent. Pot ser de la mida que vulguem. Les mides dels components s'han donat per a una ampolla de 9,6 cm de diàmetre

- Vareta d'acer inoxidable de 3 o $4 \mathrm{~mm}$

- Planxa de material ferromagnètic de 0,5 mm (llauna o similar)

- Fil de bobinar (coure vernissat) de 0,4 o 0,5 mm. Compteu uns $25 \mathrm{~m}$ per cada motor.

- $0,5 \mathrm{~m}$ de cable de connexions negre prim

- $0,5 \mathrm{~m}$ de cable de connexions vermell prim
- Planxa de llautó (els terminals d'una pila de petaca poden servir)

- Arandeles i femelles de $4 \mathrm{~mm}$. L'eix ha de passar sobradament pel seu interior

- Cinta aïllant

- 4 imants de ferreteria (els que s'utilitzen per a armaris poden servir)

- 2 piles de $4,5 \mathrm{~V}$

- Brúixola

- Adhesius (cola blanca, cola de contacte)

- Eines: Tisores de tallar planxa, tisores normals, alicates, cargol de banc, llimes, martell, serra per a metall, trepant, retolador permanent, cúter o tisores, soldador elèctric i estany

\section{CONSTRUCCIÓ DEL MOTOR}

\section{Rotor}

1. Amb el retolador permanent dibuixem els trossos de planxa que hem de retallar (fig. 1 i 2). Les mides estan pensades per a una ampolla de $9,6 \mathrm{~cm}$ de diàmetre. En tot cas, caldrà adaptar-les a l'ampolla escollida.

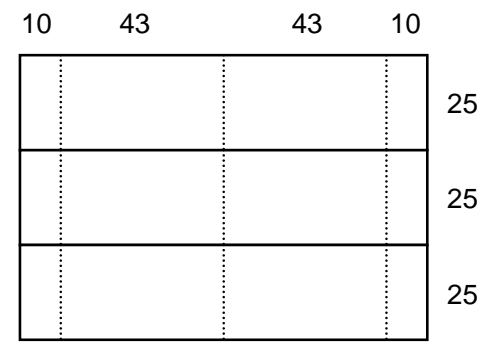

Figura 1. Mides de les tres peces de planxa A. (Cotes en $\mathrm{mm}$ ). 


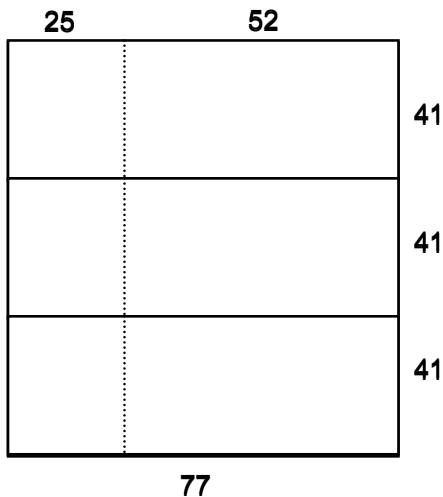

Figura 2. Mides de les tres peces de planxa B.

2. Els tallem amb les tisores de planxa. Tallarem per la línia contínua. Les línies discontínues indiquen els llocs per on doblegar. Compte a no tallar-se amb la llauna!

3. Amb l'ajut del cargol de banc donem forma a cadascun dels tres trossos de la peça A (fig. 3).

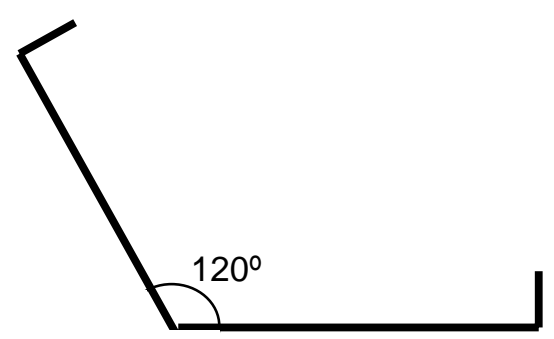

Figura 3. Perfil d'una peça A doblegada.

4. Donem forma a cadascun dels trossos B, doblegant-los per la línia de punts.

5. Emboliquem dues peces $A$ amb una peça $B$.

6. Acabem d'unir les peces A embolicant-les amb les $B$ i ja tenim el nucli del rotor.

7. Tallem $25 \mathrm{~cm}$ de vareta d'acer. Amb la llima o millor amb una mola li fem una mica de punxa en un extrem.

8. Clavem la vareta al mig del rotor... anant molt en compte de no torçar-la! Ha de sobresortir almenys $2 \mathrm{~cm}$.

\section{Bobinat}

1. Cobrim el rotor amb cinta aïllant. Hem de posar cura a cobrir bé les parts de llauna que tallen! (Si no ho fem així, tallaran el vernís que cobreix el fil de bobinar i hi haurà curt-circuits).
2. Tallem 7 o 8 metres de fil de bobinar (5 braçades aproximadament).

3. Comencem a bobinar la primera part del nucli, a $2 \mathrm{~cm}$ de distància de l'eix, cap a l'exterior. Cal deixar $10 \mathrm{~cm}$ de fil lliures al principi. Hem d'anar amb compte de fer les espires ben paral-leles. Quant acabem una capa d'espires, continuem amb una segona o tercera capes. Al final, també deixem $10 \mathrm{~cm}$ de fil lliures (fig. 4).

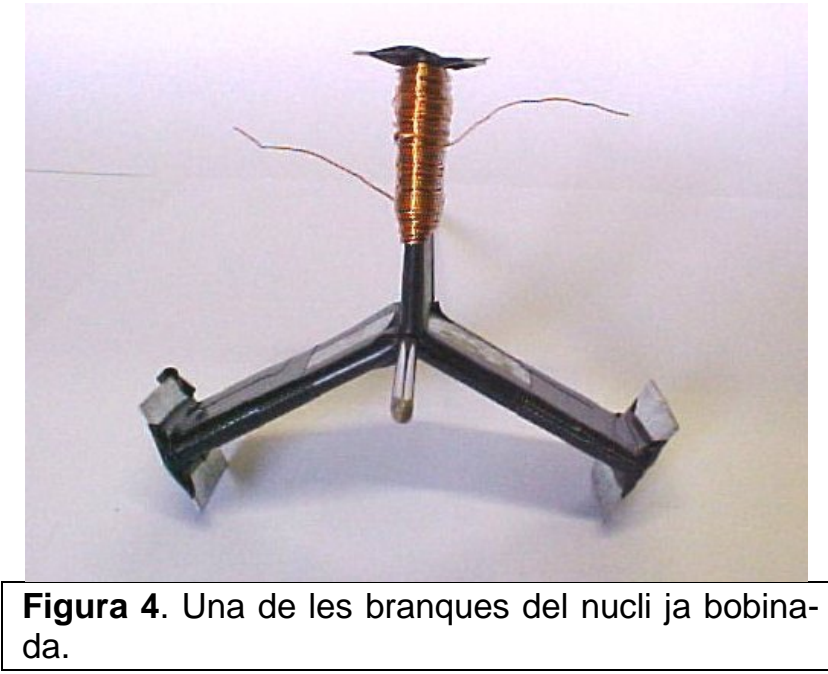

4. Repetim l'operació amb la segona part del nucli. Hem de bobinar en el mateix sentit que la primera part.

5. Completem el bobinat en la tercera part.

6. Ara tenim sis extrems de fil lliures. Els Iliguem provisionalment amb una mica de cinta perquè no es desfaci el bobinat.

7. Amb les alicates, torcem lleugerament les aletes del rotor (amb compte!) cap a l'eix. Haurem d'aconseguir que el rotor entri bé dins l'ampolla (fig. 5).

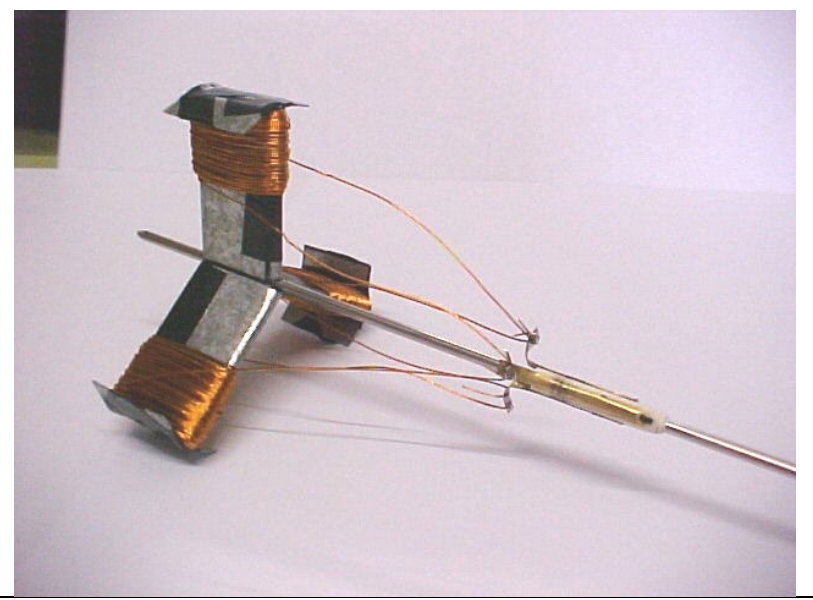

Figura 5. El rotor ja construït, a punt per ser introduiit a l'ampolla. 


\section{Preparació de l'ampolla}

1. L'ampolla ha d'estar buida, neta i eixuta. Traiem les etiquetes però conservem el tap.

2. Cal tallar l'ampolla perpendicularment al seu eix. Se'n pot eliminar un tros si és massa llarga.

3. Haurem de foradar el tap amb una broca de 3,5 o 4,5 mm per tal que l'eix hi passi sobradament.

4. Fem un altre forat igual just al centre del cul de l'ampolla.

5. Girem el cul de l'ampolla i l'introduïm al cos principal (fig. 6). Això serà la carcassa del motor.

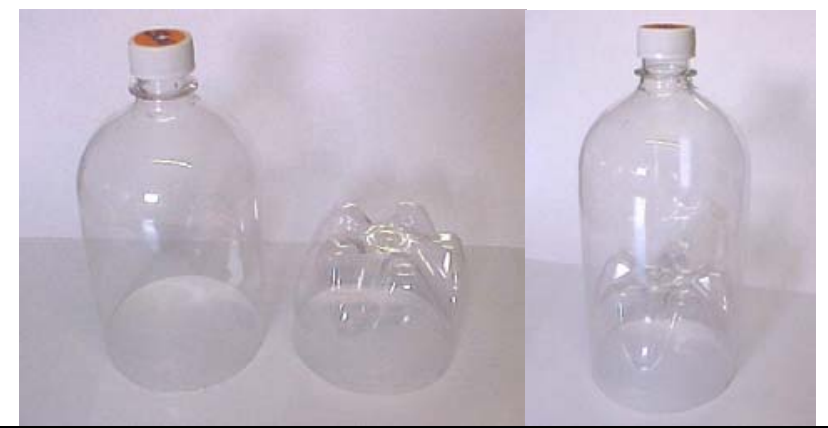

Figura 6. L'ampolla de plàstic, convertida en carcassa del motor.

6. Fem una primera prova: introduïm el rotor dins l'ampolla. Hi posem arandeles i femelles perquè el separin de l'extrem de l'ampolla, i comprovem que gira bé. El tornem a treure.

\section{Col·lectors}

1. Dibuixem tres tires rectangulars de llautó de 30 x $3 \mathrm{~mm}$ cadascuna.

2. Tallem les tires. Ja tenim les tres delgues.

3. Dibuixem i tallem un rectangle de paper de 2,5 x $10 \mathrm{~cm}$ aproximadament.

4. Haurem d'enganxar aquest paper a l'eix. En quin punt? La condició és que el conjunt "bobinat - cilindre de paper" ha de ser uns $2 \mathrm{~cm}$ més curt que l'interior de l'ampolla. Això és necessari perquè pugui girar lliurement.

5. Amb cinta ailllant unim l'extrem del rectangle de paper a l'eix del rotor. El paper ha de quedar perpendicular a l'eix. Ara enrotllem el paper fins aconseguir un gruix apreciable damunt de l'eix. Amb un adhesiu (cola blanca o similar) evitarem que es desemboliqui.

6. Ara enganxem les tres delgues al cilindre de paper amb cola de contacte, amb les següents condicions:
- El col.lector han de quedar a l'altura del coll de l'ampolla

- Les tres delgues han de quedar paral.leles a l'eix del rotor

- Han d'estar alineades amb les bisectrius del rotor

- Els extrems han de quedar lliures, perquè hi soldarem els fils que hem bobinat

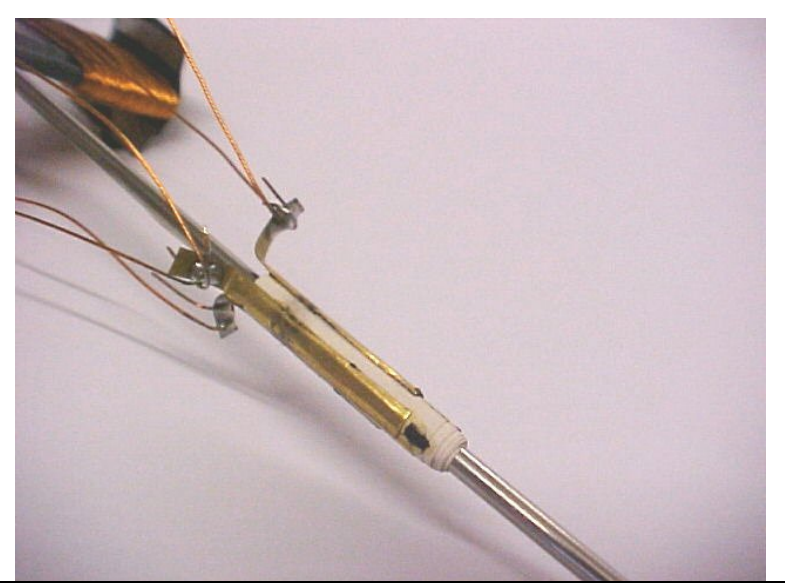

Figura 7. El col-lector.

\section{Fent connexions}

1. Deslliguem els extrems dels fils dels 3 bobinats.

2. El final d'un bobinat i el principi del següent han d'estar units i soldats a la delga que queda al mig. Per fer la soldadura, tallarem els dos fils a la mida necessària i traurem el vernís de les puntes amb paper de vidre. Un cop fet això, els soldem amb estany a la delga corresponent.

3. Ara farem una segona prova: amb una pila de petaca (en bon estat!) alimentem un dels bobinats. El nucli corresponent actua com un electroimant, és a dir, ha d'atreure els objectes de ferro.

4. Repetim aquesta prova amb cadascun dels tres bobinats. Si tots funcionen bé, el rotor ja està acabat.

\section{Escombretes}

1. Ara cal connectar el nostre motor amb l'exterior. Per això haurem de fer dues "escombretes". Tallem dues peces rectangulars de llautó de 3 x $40 \mathrm{~mm}$ aproximadament.

2. Fem dos forats de $3 \mathrm{~mm}$ al coll de l'ampolla, just al nivell on quedarà el centre del col.lector. La separació entre els centres dels forats ha de ser de 5 o $6 \mathrm{~mm}$.

3. A cadascuna de les peces de llautó li donem la forma indicada a la fotografia (fig. 8). 


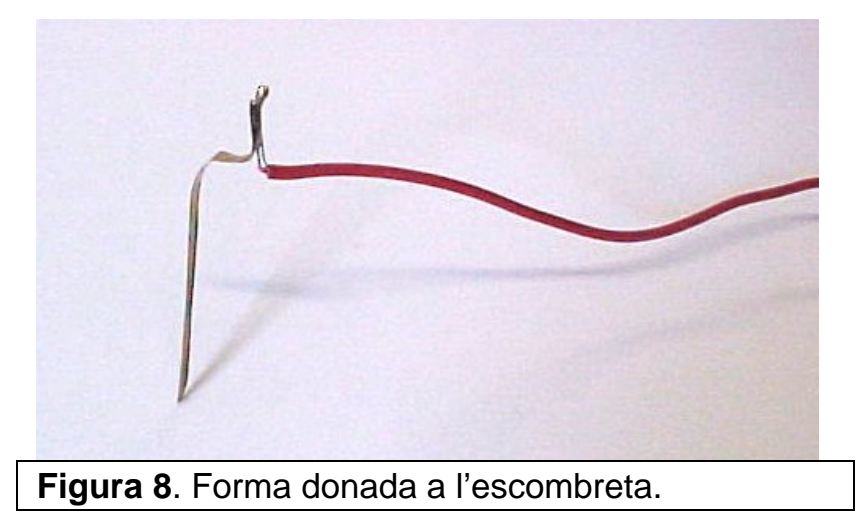

4. Introduïm les escombretes als forats, de manera que facin contacte amb el col-lector.

5. A l'extrem d'una escombreta hi soldem un cable de connexió negre (3 pams, aprox.) (fig. 9).

6. A l'extrem de l'altra hi soldem un cable vermell.

7. A l'altra punta dels cables hi podem posar terminals fasten, si en tenim, o petites pinces de cocodril.

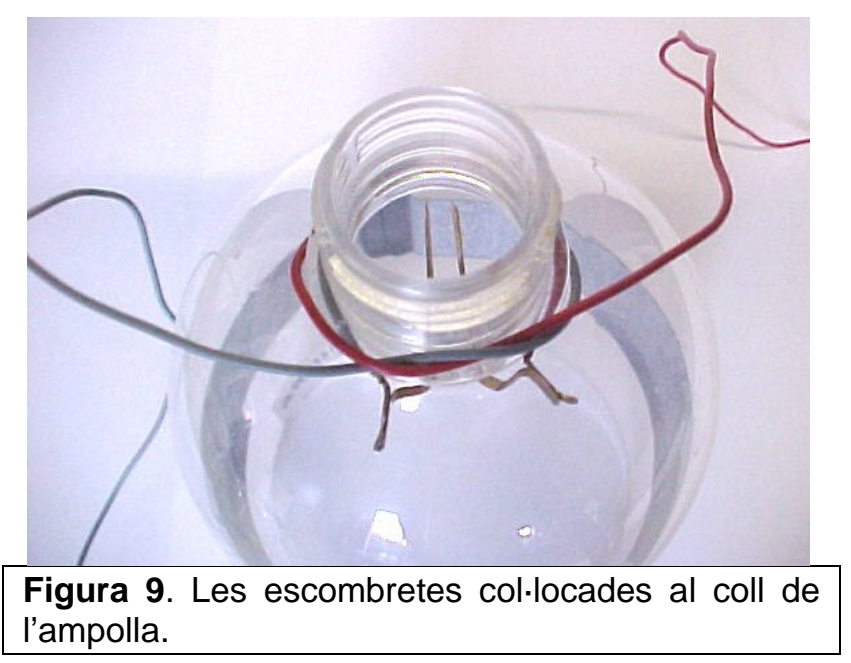

\section{Estator}

1. L'estator subministra el camp magnètic necessari perquè el rotor giri.

2. Mesurem el perímetre exterior de l'ampolla, diguem-li $P$.

3. Donat que els imants de ferreteria grans acostumen a fer $32 \times 13 \times 6 \mathrm{~mm}$ i que en posarem 2 a cada banda, haurem de tallar dos rectangles de llauna de $32 \mathrm{~mm}$ d'amplada.

4. La longitud de cada un serà $L=P / 2-12+26$ $(\mathrm{mm})$. Dibuixem i tallem les dues peces rectangulars.

5. Ara hem de donar forma semicircular a cadascuna de les peces i doblegar els extrems, fins a obtenir la forma indicada a la fig. 10.

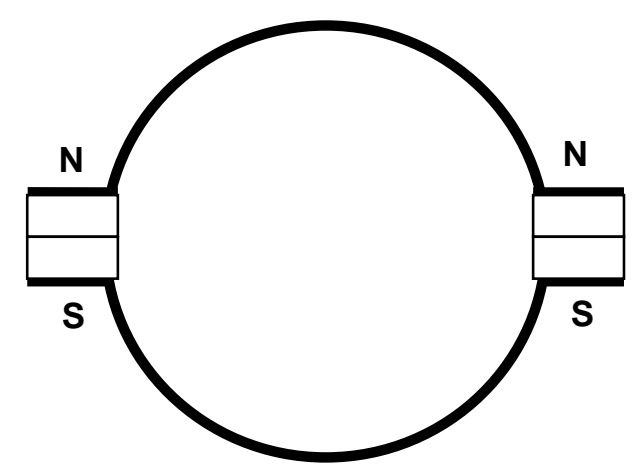

Figura 10. Disposició dels imants i les peces semicirculars.

6. Determinem la polaritat de cadascun dels quatre imants. Amb els imants i les dues peces que hem doblegat haurem d'aconseguir el conjunt indicat a la figura 10. Hem de posar els imants de manera que una peça estigui en contacte amb pols nord i l'altra amb pols sud. Finalment, unirem les dues peces amb cinta aïllant.

7. Aquest conjunt s'haurà d'adaptar a l'exterior de l'ampolla.

\section{Assemblatge del conjunt i funcionament}

1. Posem el rotor dins de l'ampolla, amb les arandeles i gruixos necessaris perquè giri lliurement.

2. Comprovem que les escombretes facin bon contacte amb el col.lector. Podem forçar aquest contacte lligant els fils de connexió al coll de l'ampolla (vegeu foto fig. 11).

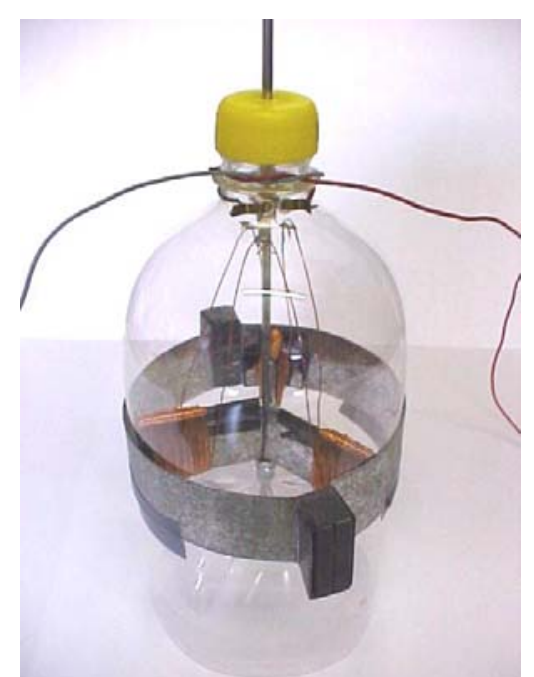

Figura 11. Tots els components del motor, ja col.locats. 
3. Posem l'estator (peces de llauna i imants) a l'exterior de l'ampolla. Alerta: El pla de simetria de l'estator ha d'estar alineat amb les escombretes

4. Alimentem el motor amb una pila de $4,5 \mathrm{~V} 0$, millor encara, amb dues piles de 4,5 V connectades en paral.lel.

5. Si no ens hem perdut en tot aquest llarg procés, el motor es posarà a girar a una velocitat considerable, tot i que el parell que proporciona és petit.

\section{ERRORS MÉS FREQÜENTS}

(Per què no funciona

si ho he fet la mar de bé...?)

1) Les escombretes no fan bon contacte

2) La polaritat dels imants no és la correcta

3) L'estator no està alineat amb les escombretes

4) Hi ha algun curt-circuit als bobinats

5) El rotor frega amb les parets

6) Si malgrat tot el motor no funciona, recordeu que la llei més important de l'univers no és la de la gravitació... sinó la de Murphy!

\section{BIBLIOGRAFIA}

Ramón Gonzalo Fernández (1981). “Construyamos un motor" .Ed. Labor. 